\title{
PELAYANAN PEMERIKSAAN KESEHATAN TELINGA HIDUNG TENGGOROKAN PADA ANAK SEKOLAH DASAR DI PEDESAAN
}

\author{
${ }^{1)}$ Edward Kurnia Setiawan Limijadi, ${ }^{2)}$ Farah Hendara Ningrum, ${ }^{2)}$ Lydia Purnama WSK ${ }^{3)}$ \\ Sigid Kirana Lintang, ${ }^{4}$ Anna Mailasari KD \\ ${ }^{1)}$ Bagian Patologi Klinik Fakultas Kedokteran Universitas Diponegoro, Semarang, ${ }^{2}$ Bagian Radiologi Fakultas \\ Kedokteran Universitas Diponegoro, Semarang ${ }^{33}$ Bagian Kedokteran Forensik dan Medikolegal Fakultas \\ Kedokteran Universitas Diponegoro, Semarang ${ }^{4}$ Bagian Ilmu Kesehatan Telinga, Hidung dan Tenggorokan \\ Fakultas Kedokteran Universitas Diponegoro, Semarang \\ 1,2,3,4) Jl. Prof. Soedarto, Tembalang, Kec. Tembalang, Kota Semarang, Jawa Tengah 50275 \\ E-mail :liemsianhok@yahoo.com,rad.pediatric@gmail.com,lydiakuntjoro@gmail.com, \\ dr.sigidkirana@fk.undip.ac.id,anna_drtht@fk.undip.ac.id
}

\begin{abstract}
ABSTRAK
Kesehatan merupakan milik setiap manusia tak terkecuali anak-anak. Keadan sehat bagi anak-anak harus mendapatkan perhatian penuh untuk menunjang perkembangan individu. Keadaan sehat pada organ telinga, hidung, dan tenggorokan perlu diwujudkan sebagai salah satu upaya menuju Indonesia Sehat. Siswa SDN Gulon 2 merupakan siswa sekolah di pedesaan yang belum pernah memeriksakan kesehatannya, oleh karena itu diperlukan pemeriksaan telinga, hidung, dan tenggorokan. Pemeriksaan telinga, hidung dan tenggorokan dilakukan dengan bantuan senter dan spatula lidah untuk menilai bagian-bagian pada ketiga organ tersebut. Ditemukan kondisi telinga normal sebanyak $48,5 \%$ sedangkan sisanya terdapat serumen; kondisi hidung normal sebanyak $78,7 \%$, sedangkan sisanya rhinitis akut; dan kondisi tenggorokan normal $66,7 \%$, sedangkan sisanya tonsilitis kronis. Tatalaksana dilakukan terhadap telinga yang terdapat serumen apabila memungkinkan. Guru dan siswa sekolah dasar diberikan pendidikan kesehatan tentang kondisi telinga, hidung, dan tenggorokan berkaitan dengan pencegahan maupun tatalaksana selanjutnya apabila keadaan memberat. Kegiatan pengabdian masyarakat perlu dilakukan kepada siswa-siswa di sekolah dasar maupun tingkat lainnya terutama di pedesaan agar mereka memperoleh kesehatan yang optimal.
\end{abstract}

Kata Kunci: telinga, hidung, tenggorokan, anak-anak, sekolah dasar

\begin{abstract}
Health belongs to every human being, including children. Every child must get full attention to be healthy to support their individual development. Healthy ears, nose and throat organs needs to be realized as an effort towards Indonesia Sehat. Gulon 2 Elementary School students are school students in rural areas who have never had their health checked, therefore ears, nose and throat examinations are needed. Examination of the ears, nose and throat is performed with flashlight and tongue spatula. Students with normal ear conditions were $48.5 \%$ while the rest had cerumen. Students with normal nose condition were $78.7 \%$, while the rest had acute rhinitis. Students with normal throat conditions were $66.7 \%$, while the rest had chronic tonsillitis. Elementary school teachers and students were given health education about conditions of the ears, nose and throat in relation to prevention and further management if the illness gets worse. Community service activities need to be carried out for students in elementary schools and other levels, especially in rural areas so that they can obtain optimal health.
\end{abstract}

Keyword: ears, nose, throat, children, elementary school

\section{PENDAHULUAN}

Periode anak usia sekolah merupakan periode pertumbuhan dan perkembangan anak yang perlu mendapatkan perhatian dan pengawasan oleh orang tua dan guru di sekolah [1]. Pengawasan tersebut bertujuan agar dapat mendeteksi gangguan kesehatan pada anak sejak dini. Pengawasan kesehatan anak meliputi kesehatan berbagai organ tubuh dengan kelainannya masing-masing tidak terlepas pada sistem organ hidung, telinga dan tenggorok (THT).

Sistem THT erat kaitannya dengan indra pendengaran, penciuman, pembicaraan juga pengecapan. Gangguan indra pendengaran yaitu pada telinga dapat berdampak pada gangguan komunikasi. Gangguan dari indra penciuman yaitu pada hidung dapat diakibatkan gangguan atau penyakit yang menimbulkan ketidaknyamanan seperti sinus, pilek atau alergi. Tidak jarang siswa sekolah merasa 
baik-baik saja atau cenderung mengabaikan keluhan THT. Di lain sisi jika keluhan tersebut diabaikan dan tidak diantisipasi sedini mungkin dapat menyebabkan gangguan tumbuh kembang. Selain gangguan pada hidung dan telinga seperti yang telah disebutkan sebelumnya, gangguan pada tenggorok dapat berkaitan dengan proses menelan dan berbicara yang juga merupakan bagian dari komunikasi [2,3].

Hal ini tidak mudah dilakukan bagi seorang guru maupun orang tua murid yang tinggal di pedesaan. Pada masyarakat pedesaan gangguan kesehatan yang masih ringan sering dianggap hal yang biasa dan sering diabaikan sehingga mereka baru datang ke fasilitas kesehatan apabila keadaan sudah sangat parah. Oleh karena itu perlu dilakukan suatu penapisan gangguan kesehatan pada anak sekolah secara dini.

Kegiatan pengabdian pemeriksaan kesehatan THT pada siswa-siswi sekolah dasar (SD) bertempat di SD Negeri Gulon 2. Desa Gulon secara geografis terletak pada Kecamatan Salam, tidak jauh dari Kecamatan Muntilan dan Kota Magelang yang memiliki pelayanan kesehatan cukup memadai. Namun sebagian besar penduduknya masih tergolong social ekonomi menengah kebawah dengan tingkat edukasi yang rendah. Faktor tersebut dapat mempengaruhi pula kesadaran untuk rutin melakukan pemeriksaan kesehatan termasuk di dalamnya kesehatan THT. Siswa-siswi SD perlu mendapatkan pemeriksaan THT secara berkala yang bertujuan untuk menapis dan mendiagnosis secara dini bila terdapat kelainan THT yang dapat mempengaruhi kemampuan belajar di rumah dan menerima pelajaran di sekolah. Edukasi kepada guru sebagai orang tua kedua anak SD juga perlu dilakukan untuk memberikan gambaran kelainan THT sehingga anak SD dapat tumbuh kembang secara optimal dengan penanganan yang komprehensif.

\section{METODE PELAKSANAAN}

Pelaksanaan pengabdian dilakukan di SDN Gulon 2 Desa Gulon Kecamatan Salam, Kabupaten Magelang. Seluruh siswa sama sekali belum pernah mendapatkan pemeriksaan kesehatan seperti siswa SD lainnya di daerah tersebut. Kegiatan pengabdian atas seizin kepala sekolah guna meningkatkan kesehatan organ THT para siswa.

Kegiatan pemeriksaan THT dilakukan pada 33 siswa menggunakan cara yang mudah yaitu menggunakan senter untuk melihat keadaan telinga bagian luar sampai dengan gendang telinga, daerah tenggorokan meliputi mukosa mulut, palatum, uvula, tonsil, dan orofaring posterior, serta hidung bagian depan meliputi mukosa dan konkha. Adapun alat lain yang digunakan yaitu spatula lidah untuk membantu melihat daerah tenggorokan.

Penanganan dilakukan kepada siswa yaitu dengan membersihkan serumen yang ditemukan dengan alat pengambil serumen apabila serumen tersebut mudah diambil. Dilakukan desinfeksi terhadap alat serumen dengan klorin lalu dikeringkan kembali untuk melakukan tata laksana yang sama kepada siswa-siswa lain jika memungkinkan.

Hasil pemeriksaan dilakukan pencatatan untuk setiap anak dan diberikan kesimpulan dari ketiga organ tersebut. Adapun indikator dari kegiatan ini yaitu menemukan kasus kelainan THT siswa SD dan melakukan penanganan sederhana.

\section{Kerangka Kerja Pengabdian}

Untuk mempermudah dalam kegiatan pengabdian ini, maka penulis membuatkan kerangka kerja kegiatan seperti pada gambar 1 berikut ini. 

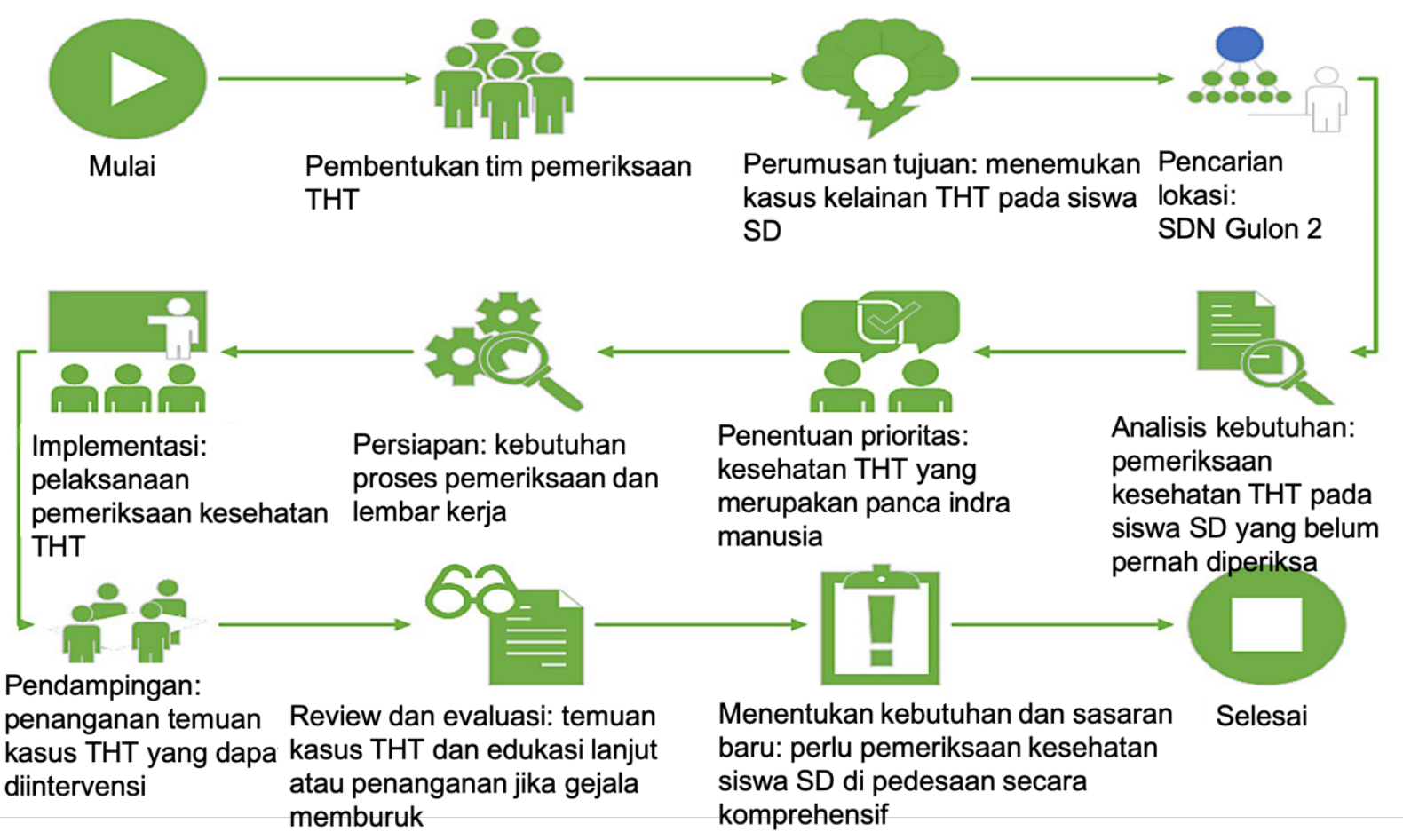

Gambar 1. Kerangka kerja kegiatan pengabdian masyarakat pemeriksaan kesehatan THT pada siswa SD di pedesaan

\section{HASIL}

Hasil pemeriksaan telinga hidung dan tenggorokan pada 33 siswa berjalan lancar. Keadaankeadaan penyulit selama pemeriksaan THT berlangsung dapat teratasi secara persuasif kepada para siswa. Jumlah siswa berdasarkan usia dan jenis kelamin dapat dilihat pada gambar 2 .

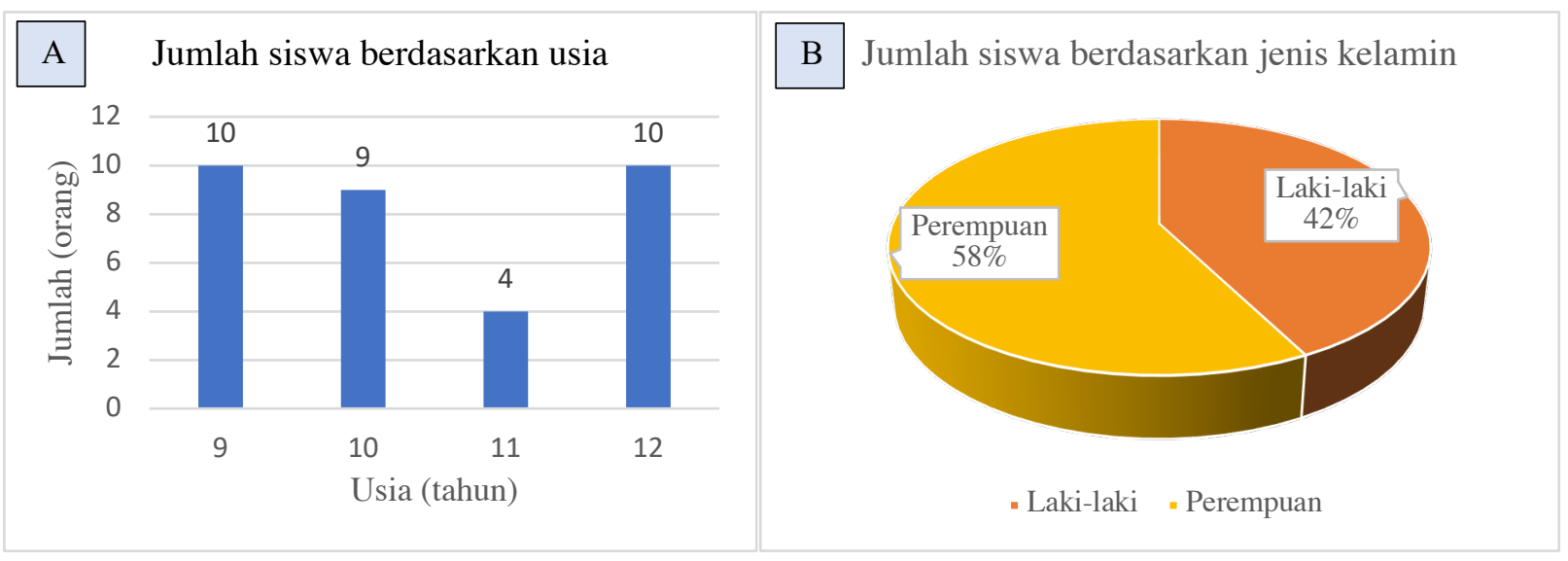

Gambar 2. Jumlah siswa berdasarkan usia (A) dan jenis kelamin (B)

Jumlah siswa paling banyak adalah pada usia 9 dan 12 tahun, sedangkan usia 11 tahun memiliki jumlah paling sedikit (Gambar 2A). Siswa berjenis kelamin laki-laki berjumlah 14 orang yang lebih sedikit daripada perempuan yaitu 19 orang (Gambar 2B). Hasil pemeriksaan THT dapat dilihat pada tabel 1 yang terbagi menjadi 3 bagian sesuai organnya.

Tabel 1. Hasil pemeriksaan telinga, hidung, dan tenggorokan siswa 


\begin{tabular}{lcc}
\hline \multicolumn{1}{c}{ Kondisi } & Jumlah (orang) & Persentase (\%) \\
\hline Pemeriksaan telinga & & \\
Normal & 16 & 48,5 \\
Serumen telinga kanan & 2 & 6,0 \\
Serumen telinga kiri & 4 & 12,0 \\
Serumen telinga kanan kiri & 8 & 33,5 \\
\hline Pemeriksaan hidung & 26 & \\
Normal & 7 & 78,7 \\
Rhinitis akut & 22 & 21,3 \\
\hline Pemeriksaan tenggorokan & & 66,7 \\
Normal & 11 & 33,3 \\
Tonsillitis kronis &
\end{tabular}

Hasil pemeriksaan tersebut diatas menunjukkan bahwa keadaan telinga siswa SD tersebut masih banyak yang normal. Terdapat beberapa siswa yang memiliki serumen di telinga kanan dan atau kiri sebanyak 14 orang. Keadaan hidung siswa juga kebanyakan normal yaitu 26 anak dibandingkan 7 anak yang terdapat rhinitis akut. Pemeriksaan tenggorokan didapatkan jumlah normal yang cukup banyak sebanyak 22 anak dibandingkan dengan yang mengalami tonsillitis kronis sebanyak 11 anak.

Tabel 2. Sebaran kondisi telinga, hidung, dan tenggorokan berdasarkan jenis kelamin

\begin{tabular}{ccc}
\hline \multirow{2}{*}{ Kondisi } & \multicolumn{2}{c}{ Jenis kelamin (orang) } \\
\cline { 2 - 3 } & Laki-laki & Perempuan \\
\hline Pemeriksaan telinga & 10 & 10 \\
Normal & 4 & 9 \\
Serumen & 11 & 14 \\
\hline Pemeriksaan hidung & 3 & 5 \\
Normal & & 17 \\
Rhinitis akut & 5 & 2 \\
\hline Pemeriksaan tenggorokan & 9 & \\
Normal &
\end{tabular}

Tabel 2 menunjukkan bahwa keadaan normal pada telinga dialami oleh siswa laki-laki maupun perempuan, sedangkan siswa yang memiliki serumen lebih banyak pada perempuan daripada laki-laki, hal ini sesuai dengan jumlah perempuan yang memang lebih banyak pada laki-laki. Kondisi normal pada hidung lebih banyak terdapat pada perempuan daripada laki-laki, akan tetapi kejadian rhinitis lebih banyak pada perempuan juga daripada laki-laki. Walaupun demikian, siswa yang memiliki kondisi hidung normal lebih banyak daripada siswa yang mengalami kondisi sakit di hidung. Pemeriksaan tenggorokan didapatkan berbeda dari organ lainnya untuk laki-laki, dimana keadaan tonsillitis kronis lebih banyak didapatkan daripada keadan normal. Tonsilitis kronis didapatkan lebih sedikit pada perempuan dibandingkan kondisi normal. Keadaan kronis pada organ tonsil ini kejadiannya lebih tinggi pada siswa laki-laki daripada perempuan.

Adanya serumen pada telinga baik kanan dan atau kiri pada siswa terjadi pada 14 dari 33 siswa yang sebenarnya hal ini bisa diatasi jika siswa maupun orang tua sadar untuk membersihkan telinga secara periodik. Siswa perempuan lebih banyak terdapat serumen pada telinga dibandingkan siswa laki-laki, sedangkan kondisi normal baik siswa laki-laki dan perempuan memiliki jumlah yang sama yaitu 10 orang. Serumen yang terdapat pada siswa-siswa tidak 
menyumbat sepenuhnya (serumen prop), sehingga dapat dilakukan tindakan pengambilan serumen pada siswa. Alat pengambil serumen juga telah diperhatikan dengan didesinfeksi terlebih dahulu sebelum digunakan untuk siswa lainnya. Tidak ditemukan kecurigaan tuli saraf maupun kelainan lainnya pada kegiatan pemeriksan telinga ini.

Produksi serumen (kotoran telinga) adalah proses normal pada manusia karena bertujuan melembabkan kulit saluran pendengaran eksternal dan melindunginya dari infeksi, memberikan penghalang bagi serangga dan air. Serumen biasanya dikeluarkan dari saluran telinga secara spontan melalui gerakan rahang alami. Namun, pada individu tertentu, mekanisme pembersihan diri dapat mengalami kegagalan sehingga serumen dapat menyumbat saluran pendengaran dan menekan membran timpani. Hal tersebut berpotensi menyebabkan ketidaknyamanan telinga, gangguan pendengaran konduktif dan sensasi gatal-gatal. Kejadian serumen yang menyumbat terjadi hingga $10 \%$ pada anak-anak [4].

Terdapat beberapa penelitian di Indonesia mengenai hubungan kejadian serumen obsturan dengan gangguan pendengaran pada siswa sekolah. Survei oleh Perhati Fakultas Kedokteran Universitas Indonesia di beberapa sekolah di 6 kota di Indonesia menunjukkan prevalensi serumen prop pada anak sekolah adalah sekitar 30-50\% [5]. Penelitian yang dilakukan oleh Charisma pada sebuah sekolah dasar di Banda Aceh mendapati 30 dari 51 siswa dengan serumen obsturan dan 14 pelajar dengan tuli konduktif serta terdapat hubungan antara serumen obsturan dengan kejadian gangguan pendengaran [6]. Penelitian lainnya oleh Alriyanto pada beberapa sekolah dasar di Kota Semarang juga mendapati adanya hubungan serumen obsturan dengan gangguan pendengaran ringan-sedang [7]. Taba dkk juga mendapati angka kejadian serumen prop mencapai $51 \%$ pada 2 buah sekolah dasar di Jakarta Barat. Gangguan pendengaran pada anak sekolah rupanya masih banyak dijumpai dan memerlukan upaya deteksi sedini mungkin mengingat peranannya dalam proses komunikasi verbal, baik menerima maupun menyampaikan pesan. Hal tersebut juga dapat mempengaruhi siswa dalam bersosialisasi dengan teman dan guru di lingkungan sekolah hingga mempengaruhi keadaan emosional siswa [5].

Keadaan lain yang didapat pada pemeriksaan hidung yaitu rhinitis akut. Keadaan tersebut didapat dengan dasar bahwa siswa pada saat pemeriksaan mengalami pilek dan konkha mengalami kemerahan (hiperemis). Kejadian ini sebesar 21,3 persen, sedangkan 78,7 persen mengalami kondisi normal, tidak terdapat kelainan pada bagian hidungnya. Kondisi hidung normal siswa perempuan lebih banyak daripada siswa laki-laki. Kedua jenis kelamin ini memiliki jumlah kondisi normal lebih banyak daripada mereka yang mengalami rhinitis akut. Rhinitis merupakan radang dan iritasi yang terjadi di membran mukosa di dalam hidung. Peyakit rhinitis dapat terbagi menjadi 2 yaitu rhinitis alergi dan rhinitis non-alergi [8]. Prevalensi kejadian rhinitis pada usia 6-7 tahun adalah sekitar 8,5\% sedangkan pada usia 13-14 tahun sekitar 14,6\% berdasarkan riset dari The International Study for Asthma and Allergies in Childhood (ISAAC) pada negara-negara di kawasan Asia-Pasifik. Gejala rhinitis meliputi hidung tersumbat, gatal, pilek, serta bersin-bersin tentunya dapat menimbulkan distraksi atau gangguan konsentrasi selama jam belajar di sekolah maupun di rumah [9]. Guru dan siswa diberikan pengertian bahwa apabila keadaan memberat perlu untuk datang ke pusat kesehatan untuk diberikan pengobatan lebih lanjut. Selain itu, siswa juga diberikan pengertian agar tidak selalu membeli minuman ringan dingin serta menjaga kesehatan dengan pola makan yang seimbang. Perilaku hidup bersih dan sehat juga perlu diterapkan guna pencegahan penyakit rhinitis agar tidak berulang.

Pemeriksaan pada organ ketiga yaitu tenggorokan didapatkan sebesar 66,7 persen siswa dalam kondisi normal, sedangkan 33,3 persen mengalami tonsillitis kronis. Keadaan ini diambil dengan dasar bahwa tonsil mengalami pembesaran dan agak pucat. Berdasarkan jenis kelamin, kondisi tonsilits kronis lebih banyak diderita oleh siswa laki-laki daripada perempuan dan siswa laki-laki mengalami tonsilitis lebih banyak daripada siswa laki-laki yang normal. Siswa perempuan hanya terdapat 2 orang yang mengalami tonsilits kronis, sedangkan 17 orang 
memiliki kondisi tenggorokan normal.

Tonsilitis kronik merupakan penyakit yang paling sering terjadi pada tenggorokan dengan insiden tersering pada usia anak sekolah dasar, Tonsilitis kronis sering terjadi karena adanya radang yang berulang akibat komplikasi tonsillitis akut yang tidak mendapat terapi adekuat dan disertai dengan faktor predisposisi lainnya seperti hygiene mulut yang buruk, polusi udara, kelelahan fisik, status gizi, daya tahan tubuh, konsumsi jenis makanan dan status social ekonomi keluarga [10]. Penelitian yang dilakukan oleh Kishve pada pedesaan di India, tonsillitis kronik mayoritas terjadi pada usia 5-14 tahun dengan prevalensi sebesar 66,3\% dan berasal dari status ekonomi rendah $(61,2 \%)$ [11]. Penelitian serupa di Indonesia dilakukan oleh Harrypana pada siswa sekolah dasar di Karangasem, Bali didapatkan 12,46\% dan 17,2\% siswa dengan tonsillitis kronik pada 2 sekolah dasar [12]. Terdapat persamaan kisaran umur serta angka kejadian antar beberapa penelitian dan sejalan dengan hasil penelitian pada siswa SDN Gulon 2.

Salah satu faktor predisposisi yang menjadi perhatian di SDN Gulon 2 adalah jenis makanan yang sering dikonsumsi siswa, yaitu minuman dingin tdengan pemanis buatan dan mengandung bahan pengawet, terutama siswa laki-laki. Jenis makanan tersebut relatif murah dan mudah didapat di sekolah-sekolah bahkan area pedesaan. Faktor predisposisi lain yang perlu diperhatikan adalah oral hygiene yang buruk [13]. Area mulut yang kurang terawat kebersihannya dapat menjadikan lingkungan yang baik bagi kuman patogen seperti Streptokokus beta hemolitikus sebagai bakteri penyebab tonsillitis kronik. Oleh karena itu siswa dan guru diberikan pengertian untuk mengurangi konsumsi jenis makanan dan minuman tersebut serta lebih meningkatkan oral hygiene. Mereka juga diberi pengertian apabila mengalami nyeri telan yang berat pada suatu saat, maka siswa perlu dibawa berobat ke pusat kesehatan.

Peran guru dan orang tua sangat penting untuk menjamin kesehatan anak-anak usia sekolah di segala tingkat. Peran ini ada apabila guru dan orang tua memiliki pengetahuan dan kemauan yang kuat untuk mewujudkan kesehatan bagi anak-anak mereka. Selain itu, peran pemerintah juga penting dalam peningkatan kesehatan anak sekolah melalui berbagai program kesehatan yang diterapkan kepada sekolah-sekolah terutama di pedesaan.

\section{Dokumentasi Kegiatan}
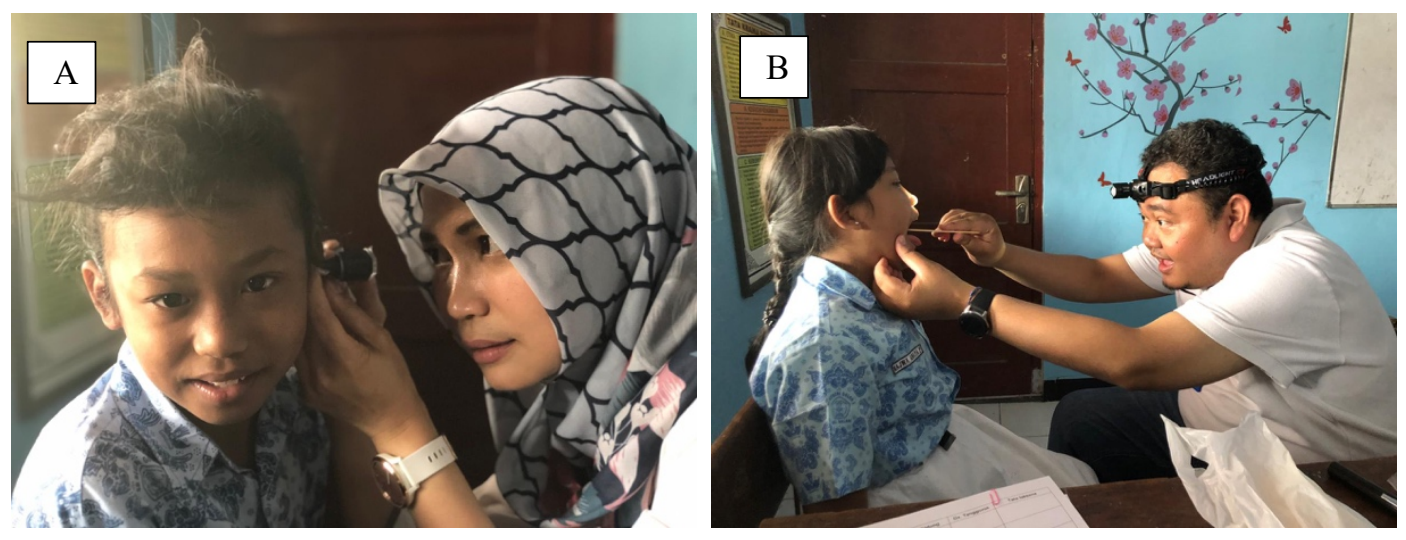

Gambar 3. Pemeriksaan kesehatan telinga yang dilakukan oleh salah satu pelaksana pengabdian masyarakat untuk melihat keadaan telinga bagian luar sampai dengan gendang telinga (A). Pemeriksaan tenggorok oleh salah satu pelaksana pengabdian masyarakat untuk mengidentifikasi kelainan mulut, palatum, tonsil, serta orofaring menggunakan bantuan spatula lidah (B). 


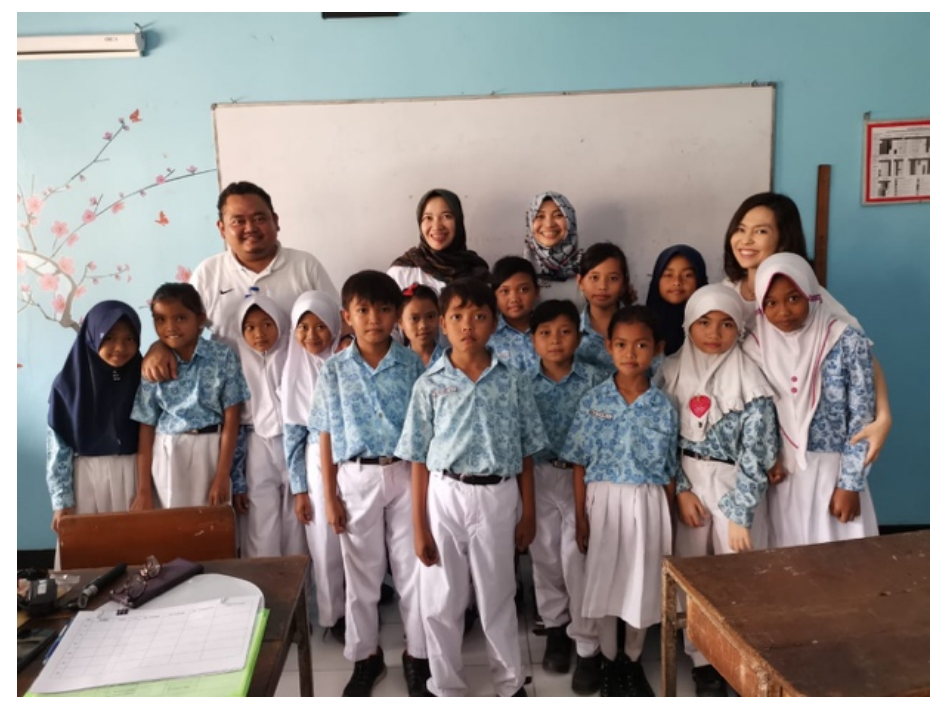

Gambar 4. Foto bersama peserta pengabdian masyarakat siswa SD dengan pelaksana pengabdian masyarakat setelah pemeriksaan THT selesai dilakukan.
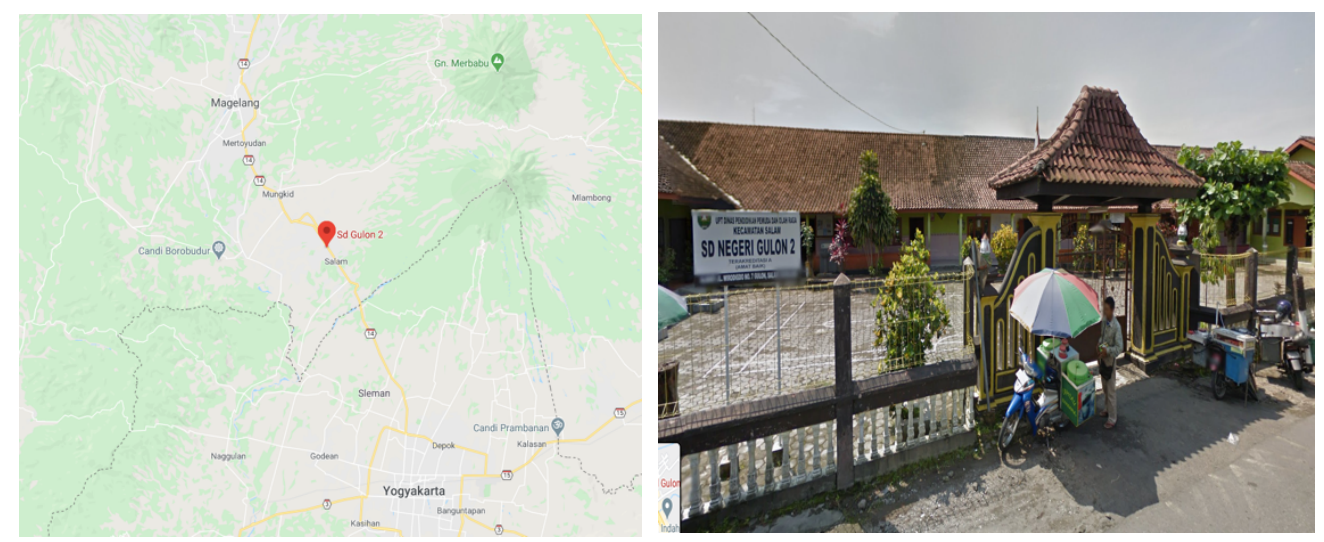

Gambar 5. Lokasi kegiatan pengabdian masyarakat pelayanan pemeriksaan THT di SDN Gulon 2

\section{KESIMPULAN}

Terdapat penemuan kasus pada telinga, hidung dan tenggorokan siswa SDN Gulon 2 berupa serumen pada telinga, rhinitis akut, dan tonsilits akut. Sebagian besar siswa memiliki keadaan telinga, hidung dan tenggorokan normal. Dilakukan edukasi kepada guru dan siswa untuk memeriksakan lebih lanjut apabila terdapat kelainan yang memberat. Pemeriksaan kesehatan serupa perlu dilakukan kepada siswa-siswa sekolah dasar untuk penemuan kasus kesehatan serta melakukan edukasi peningkatan kesehatan bagi guru dan siswa-siswa sekolah dasar.

\section{DAFTAR PUSTAKA}

[1] Latifa U. Aspek Perkembangan pada Anak Sekolah Dasar: Masalah dan Perkembangannya. Academica. 2017;1(2):185-96.

[2] Fasunla AJ, Samdi M, Nwaorgu OG. An audit of Ear Nose and Throat diseases in a tertiary health institution in South-western Nigeria. Pan Afr Med J. 013; 14:1.

[3] Wooles N. Speech and language delay in children: a case to learn form. Br J Gen Pract. 2018; 68(666): 47-8.

[4] Michaudet C, Malaty J. Cerumen Impaction: Diagnosis and Management. Am Fam Physician. 2018;98(8):525-9. 
[5] Martini E, Probandari A, Pratiwi D, Sumardiyono. Skrining dan edukasi gangguan pendengaran pada anak sekolah. Ind J on Med Sci. 2017;4(1):110-8.

[6] Charisma PM. Hubungan serumen obsturan dengan gangguan pendengaran di Madrasah Ibtidaiyah Negeri Ulee Kareng. Fakultas Kedokteran Universitas Syiah Kuala Aceh. 2016

[7] Alriyanto CY. Pengaruh serumen obsturan terhadap gangguan pendengaran (Studi kasus pada siswa kelas V SD di Kota Semarang). Fakultas Kedokteran Universitas Diponegoro Semarang. 2010

[8] Hardjojo A, Shek LPC, Bever HPS, Lee BW. Rhinitis in children less than 6 years of age: current knowledge and challenges. Asia Pac Allergy. 2011;1(3):115-22.

[9] Mir E, Panjabi C, Shah A. Impact of allergic rhinitis in school going children. Asia Pac Allergy. 2012;2(2):93-100.

[10] Khasanov SA, Asrorov AA. Prevalence of chronic family tonsillitis and its prevention. Vestn Otorinolaryngology. 2006;4:38-40.

[11] Kishve SP, Kumar N, Kalakoti P. Ear, nose and throat disorders in paediatric patients at a rural hospital in India. Australasian Medical Journal. 2010;3(12):786-90.

[12] Harrypana IGNG, Putra DGAE. Distribusi tonsillitis kronis pada siswa di SD 1 Ubung Denpasar dan SD 2 Abang Karangasem. Medicina. 2019;50(2):281-8.

[13]Fakh IMF, Novialdi, Elmatris. Karakteristik Pasien Tonsilitis Kronis pada Anak di Bagian THT-KL RSUP Dr. M. Djamil Padang tahun 2013. Jurnal Kesehatan Andalas. 2016;5(2):43642. 